\title{
Malaysian public survey on the current carry-on luggage handling onboard commercial transport aircraft
}

\author{
Fairuz I Romli*, Nur Hidayah Ariffin \\ Department of Aerospace Engineering, Faculty of Engineering, Universiti Putra Malaysia, \\ 43400 Serdang, Selangor, Malaysia \\ *Corresponding author E-mail:fairuz_ir@upm.edu.my
}

\begin{abstract}
The current handling of carry-on luggage inside the aircraft cabin has led to several issues such as inefficient boarding and disembarking processes. Due to the number and size of current carry-on luggage, the boarding process has been slowed down due to aisle blocking and luggage overcrowding in the overhead storage bins. To improve this situation, an automated cabin luggage system has been proposed. A public survey has been conducted to explore the general passengers' perception of current carry-on luggage handling inside the cabin and to identify potential rooms for improvement that can be catered by the automated cabin luggage system. The responses obtained from the survey indicate that the current carry-on luggage handling does have several weaknesses that can be improved by the proposed automated system.
\end{abstract}

Keywords: carry-on luggage; aircraft cabin; automated system; passenger perception; market study.

\section{Introduction}

Today, many people have increasingly chosen air transportation as their travel mode. This situation can be principally contributed to the rise of low-cost airlines, which has made flight services more affordable to greater mass public. In Malaysia, the number of domestic flight passengers has been on increase trend from year to year, with more than 48 million passengers transported domestically in 2016 [1]. The local low-cost airlines like AirAsia, FireFly and Malindo have been dominating the domestic flight market by capturing more than 65\% market shares in 2017 [2]. Nevertheless, the increase in market demands also means that the level of market competition between airlines has also risen up. To attract more passengers to their flight services, most airlines have been looking for ways to differentiate themselves from their competitors. Airline service quality is one of the most critical factors that will likely influence airline selection [3] and some of the perceived important service quality attributes include ticket price, safety, seat comfort, in-flight meals and others [4]. To this effect, there have been studies and new system development to improve the current flight services including reducing seating discomfort among passengers [5], offering automated in-flight meal and waste collection services [6], and also improving the boarding process [7], just to name a few examples. With regards to the latter, one of the main reasons for delays in aircraft boarding process is the carry-on luggage [8], which is of high interest in this study.

It is known that turnaround time is really important to the airlines. As reported in Ref. [9], a major airline can save more than USD 50 million for a single minute reduction in the turnaround time for across all of its flights. In addition, passengers would also highly appreciate minimum waiting time and a smooth boarding process, eliminating any potential cause for trip delays [10]. Although the boarding process is only one of the components of the turnaround time event set, which include other activities such as galley servicing, cabin cleaning, aircraft refueling, cargo loading and others, it is also the one that is relatively adaptive to change and modification [11]. This means that other activities during turnaround time event might not have many opportunities for process alteration or change in comparison to the boarding process. The aircraft boarding rate these days is reduced to only nine passengers per minute, a steep reduction from 20 passengers per minute back in 30 years ago [12]. One of the reasons for this declining rate has been identified as the increased passengers' carry-on luggage. This is particularly evident in recent years as many airlines start to increase their charges for checked luggage, which has subsequently driven many passengers to bring more and heavier carry-on items into the cabin [13]. Several issues have been raised regarding carry-on luggage effects on the efficiency of aircraft boarding process. Firstly, the number and size of the carry-on luggage can influence the boarding process time due to aisle blockage caused by the time taken to place the luggage in the overhead bins [14]. Secondly, distribution of carry-on luggage is not even throughout the plane and some of the passengers might have to store their luggage in the overhead bins that are not at their assigned seating [15]. This overcrowding of luggage situation can cause aisle blockage as passengers search for available rooms in the other overhead bins to store their bags. Last but not least, there have been instances when carry-on items fall from the overhead bins during the storing of luggage. This can slow down the boarding process and worst, can also cause injuries. A conducted survey among flight attendants has shown that there have been quite a number of occurrences where carry-on luggage fell from overhead storage compartment and hit them, resulting in some injuries [13].

To further improve the efficiency of the aircraft boarding process, particularly in handling the carry-on luggage, an automated cabin luggage system has been proposed. As indicated in Figure 1, this system is expected to ease the aircraft boarding process by freeing 
passengers from having to bring their carry-on luggage with them through the narrow aisle and then store them in the overhead bins. This situation can speed up the process of getting the passengers to their assigned seats and avoid any aisle blockage. In addition, possibility of having accidents with falling carry-on luggage from the overhead bins or lost items has also been eliminated with this automated system since they are stored in a more secured place. It is envisioned that the passengers' access to their carry-on luggage can still provided at the automated stations during flight, though it might be more restricted than in the current condition. The overall mechanism for this automated system is under conceptual development and findings from this study will help to establish design requirements to be considered for the system.

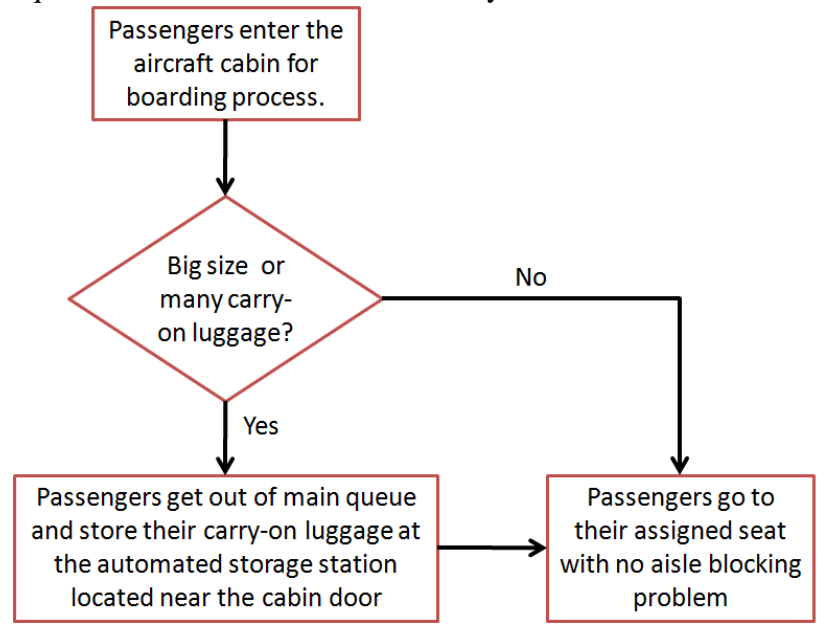

Fig. 1: Operational flowchart of proposed automated cabin luggage system

\section{The passenger survey}

A public survey has been conducted among the Malaysian public to establish the general perception of flying passengers with regards to current carry-on luggage handling in the aircraft cabin. In total, 521 people have participated in the survey, which is carried out at several hotspots for aircraft passengers including the Kuala Lumpur International Airport $1 \& 2$ and Sultan Abdul Aziz Shah Airport. This is done to ensure a high relevancy of survey respondents to the target participants, which are people who have experiences in flying with commercial airlines. From the reported Malaysian transport statistics, total number of domestic flight passengers catered by airlines to and from the local airports is estimated to be about $47,965,835$ people in 2016 [1]. Taking this as the total population size of the target participants for the conducted public survey, subsequent statistical analysis results using the collected data from a sample size of 521 roughly corresponds to $95 \%$ confidence level with \pm 4.29 confidence interval. This is based on the standard calculation for sample size and confidence level. Of the total 521 respondents, $55.5 \%$ are female and the majority of them are within the age group of 18 to 25 years old. More details on the demographic of the survey respondents are presented in Table 1.

In general, apart from personal background of the respondents, the distributed survey questionnaire is comprised of questions that are related to their travel behaviour in using the commercial air transport, their comments and suggestions with regards to the current carry-on luggage handling and its potential improvements.

\subsection{Air travel behaviour}

When asked about their common purpose when choosing commercial air transportation for travel means, majority of the respondents indicated that their trips have been mostly for vacation. The second most cited reason for flying is personal trip whereas business travel is third on the list. On the other hand, when questioned about their frequent choice of airlines for the flight trips, low-cost airlines with complimentary checked-in luggage are the top pick, followed far behind by the low-cost airlines with no complimentary checked-in luggage and also the premium airlines with complimentary checked-in luggage. Furthermore, majority of the respondents or $56.1 \%$ of them prefer to have only carry-on luggage during their travel while $14 \%$ of them stated that they usually have both carry-on and also checked-in luggage. A strong $75 \%$ of them believed that carry-on luggage should be allowed inside the cabin, with only $25 \%$ of them are against it. Summary of details regarding obtained responses for these questions are presented in Figure 2.

Based on the collected responses in this section, it can be inferred that most flight passengers tend to choose airline services based on cheaper flight ticket prices. This is evident when low cost airlines are consistently favoured against premium airlines, which usually charge higher flight ticket prices. In terms of checked-in luggage, most passengers prefer to have it as a complimentary service but many low-cost airlines do not provide this service for free. The preference to have complimentary checked-in luggage also indicates that the passengers typically travel with many travel items, which they tend to bring onboard into the cabin as their carry-on luggage whenever they can to avoid extra charges. This notion is in line with the strong support to allow carry-on luggage into the cabin.

\subsection{Perception of current carry-on luggage handling}

With more passengers tend to carry a substantial carry-on luggage into the aircraft cabin, their handling process becomes more important. From the responses obtained in the conducted public survey, $36.9 \%$ of the survey respondents stated that the current carryon luggage handling is not satisfactory while another $53.2 \%$ said that the process could have been improved. This signifies a strong dissatisfaction with their flight experiences regarding the carry-on luggage.

The survey respondents have been asked to rate current handling process in terms of seven aspects as shown in Figure 3. The rating is conducted based on a Likert scale between 1 to 5 , with 1 corresponds to very dissatisfied while 5 refers to very satisfied. It can be observed in Figure 3 that none of the evaluation aspects is rated higher than 4, which indicates that the passengers are hardly satisfied with the current handling process. There are three criteria that have been rated lower than rating of 3 in average: user-friendliness, restriction on size and dimension of the luggage, and also safety of the carry-on luggage while being stored in the overhead compartment. The low dissatisfied rating for user-friendliness may be due to some of the difficulties faced by the passengers in carrying their carry-on luggage through the narrow aisle and lifting them up for storage in the overhead bins.

Table 1: Demographics of survey respondents

\begin{tabular}{|l|c|}
\hline Demographic characteristics & Percentage (\%) \\
\hline nder & \\
Male & 44.5 \\
Female & 55.5 \\
Age & \\
Under 18 & 8.0 \\
$18-25$ & 34.9 \\
$26-35$ & 32.1 \\
36 and above & 25.0 \\
Nationality & \\
Malaysian & 52.7 \\
Non-Malaysian & 47.3 \\
\hline
\end{tabular}




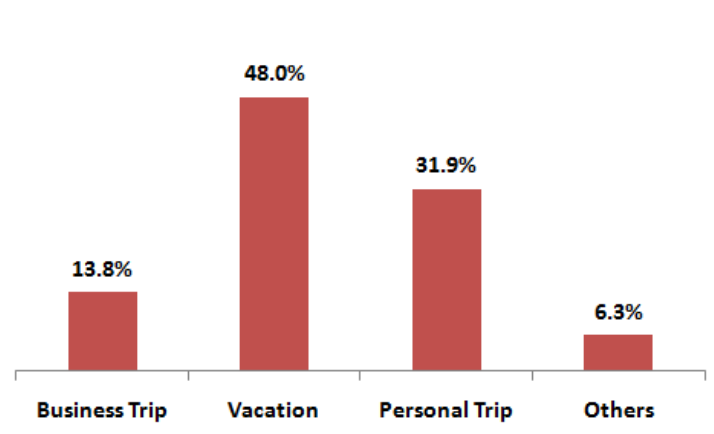

(a) Most likely purpose for flight trips

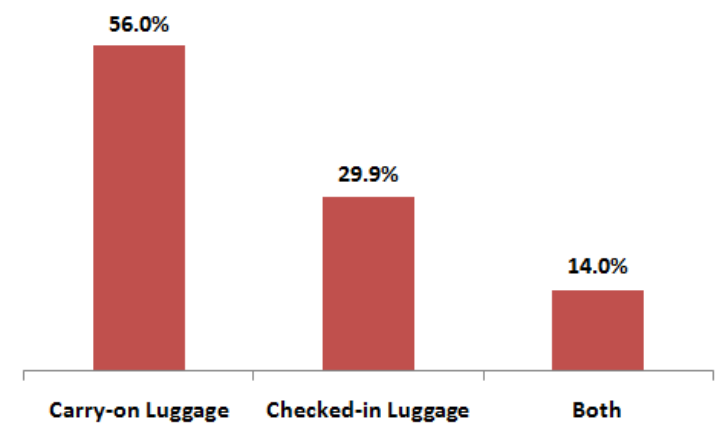

(b) Travel preference

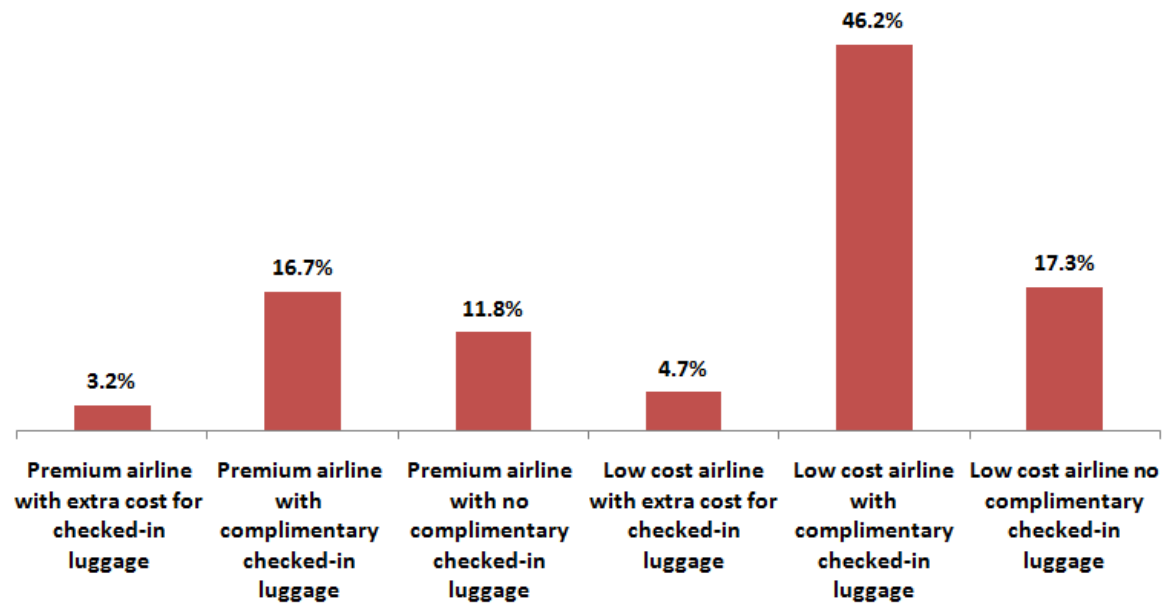

(c) Frequent choice of airlines

Fig. 2: Responses in travel behavior section of the survey questionnaire

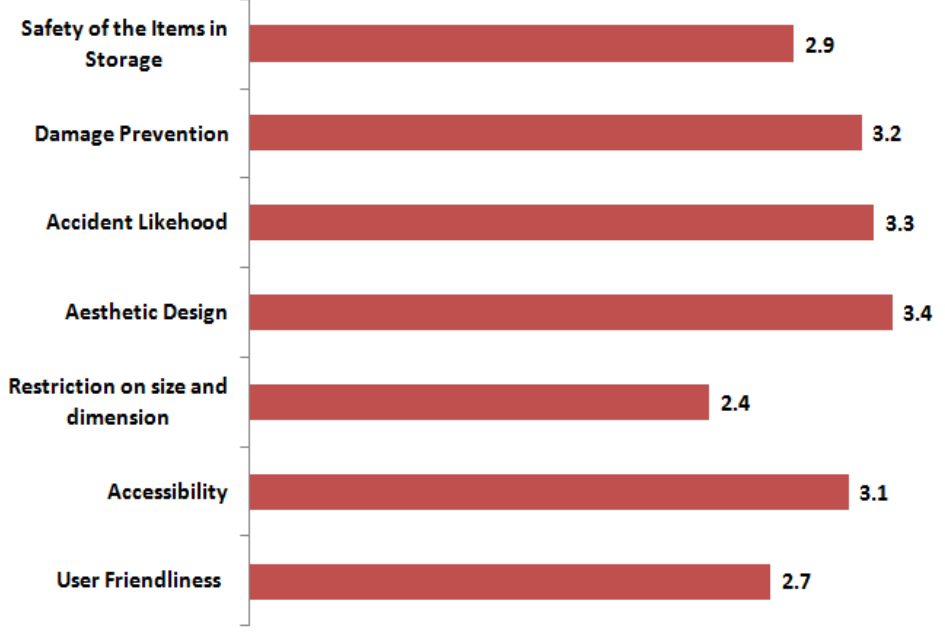

Fig. 3: Average rating given to current carry-on luggage handling

On the other hand, the restriction on the size and dimension of the luggage means that some personal items might not be permissible to be carried on into the cabin, causing difficulty to the passengers. This also corresponds to the inability of some luggage or items to fit into the overhead storage bins. Last but not the least, with lack of security feature on the shared overhead storage bin, some of the carry-on items can be easily accessed by other passengers onboard and this creates a possible safety issue.

To further strengthen the impression that current carry-on luggage handling could be improved, survey respondents have been asked about their own experiences with regards to the carry-on luggage handling. Table 2 details out several negative experiences that the respondents have had during previous flight trips in relation to the carry-on luggage handling. It is not surprising that the most complaints are regarding aircraft boarding and disembarking processes, where the aisle blocking instances tend to slow down the process and cause the long waiting time. In support of previous comments made for the low rating obtained in some aspects of current carryon luggage handling, the survey respondents have also indicated that they do have issues with the storing of their luggage into the overhead bins due to their height and the sharing of storage compartment with other passengers who can easily accessed their personal items. These are among some of the issues that need to be considered and resolved by the proposed cabin luggage system. 
Table 2: Negative experiences regarding carry-on luggage handling

\begin{tabular}{|l|c|}
\hline \multicolumn{1}{|c|}{ Scenario } & Percentage (\%) \\
\hline $\begin{array}{l}\text { Difficult to store your carry-on luggage into the } \\
\text { overhead storage compartment due to height }\end{array}$ & 28 \\
\hline $\begin{array}{l}\text { Disturbed from your rest when other passengers } \\
\text { try to access their stored items in the overhead } \\
\text { storage compartment }\end{array}$ & 32 \\
\hline $\begin{array}{l}\text { Feel rather uncomfortable sharing the storage } \\
\text { compartment with other passengers due to their } \\
\text { accessibility to your personal items }\end{array}$ & 57 \\
\hline $\begin{array}{l}\text { Have to wait long to board and disembark from } \\
\text { the aircraft because of aisle blocking by other } \\
\text { passengers }\end{array}$ & 5 \\
\hline $\begin{array}{l}\text { Some items fell out from the overhead storage } \\
\text { compartment }\end{array}$ & \\
\hline $\begin{array}{l}\text { Your items are either lost or damaged while in the } \\
\text { overhead storage compartment }\end{array}$ & \\
\hline
\end{tabular}

\subsection{Potential improvement of carry-on luggage handling}

With their comments regarding current carry-on luggage handling, the survey respondents are asked several questions on the potential improvement that they would like to see implemented to the service. When introduced with the idea of automated cabin luggage system, more than $61 \%$ of the respondents think that it is a good effort to improve the current carry-on luggage handling, with only $8 \%$ are not supportive of the idea while the other $31 \%$ are neutral about it. When asked whether they are willing to pay higher flight ticket price to have the automated system onboard, $83 \%$ of them have given affirmative response with $52 \%$ mentioned only a slight increase. Table 3 tabulates the calculated importance score based on the ranking given by the survey respondents for several characteristics that could improve the current carry-on luggage handling on the automated system. In this case, the survey respondents are asked to rank the characteristics based on their perceived importance and the score is given based on the ranking. It is observed that the allocated luggage capacity and the safety of stored items are two most important considerations by the passengers. This is very much in line with the comments on limitations of the current carry-on luggage handling. On contrary, the aesthetic value of the system design is not a major concern for the passengers as it has been the lowest ranked criterion for most survey respondents.

Table 3: Importance score of criteria for automated cabin luggage system

\begin{tabular}{|l|c|}
\hline \multicolumn{1}{|c|}{ Characteristics } & Score \\
\hline Safety of stored items & 2722 \\
Allocated carry-on luggage capacity & 2281 \\
Strength of the storage compartment & 1913 \\
Accessibility to the stored items & 1899 \\
User-friendliness of the system & 1490 \\
Aesthetic value of the system & 636 \\
\hline
\end{tabular}

Furthermore, as should be expected, the implementation of automated cabin luggage system might cause some differences in the way that carry-on luggage are being handled in comparison to the current situation. The survey participants are asked whether they are willing to compromise certain flexibility in order to have the automated system onboard. Some of the anticipated design limitations or constraints for the system are listed in the questionnaire and the responses obtained are as tabulated in Table 4. It is shown that the passengers are not ready to sacrifice luggage capacity or the types of items that they can bring into the cabin, which is evident from the low approval responses. On the other hand, close to $64 \%$ of them are okay with the expected small increase in ticket price whereas more than $51 \%$ of them can accept the limited access to their stored items.

Table 4: Approval of expected limitations for the automated system

\begin{tabular}{|c|c|}
\hline Limitation & Percentage Approval (\%) \\
\hline Small increase in ticket price & 63.5 \\
\hline $\begin{array}{l}\text { Limited size and dimension for carry- } \\
\text { on luggage }\end{array}$ & 12.1 \\
\hline Limited access to stored items & 51.4 \\
\hline $\begin{array}{l}\text { Restriction of items that can be } \\
\text { brought onboard }\end{array}$ & 24.2 \\
\hline
\end{tabular}

\section{Conclusion}

Based on the results of the conducted public survey, a few conclusions regarding the carry-on luggage handling can be made. There are indeed some rooms of improvement to increase the efficiency of the process according to the given assessments and comments by the survey respondents. The introduction of idea for an automated cabin luggage system can be said to be positively received and several criteria for its design development have been established from the survey responses. On the whole, the information obtained from this survey study can be utilized to either improve the current process or develop a new system for carry-on luggage handling process.

\section{Acknowledgement}

The authors would like to thank the airport management of KLIA KLIA2 and Sultan Abdul Aziz Shah Airport for allowing the public survey being conducted at their premises. In addition, the authors also thank some survey participants from AIROD Sdn. Bhd.

\section{References}

[1] Ministry of Transport Malaysia (2017), Transport Statistics Malaysia 2016

[2] Aliman KH (2017), Competition easing in Malaysian skies as AirAsia dominates. The Edge Malaysia

[3] Truitt L \& Haynes R (1994), Evaluating service quality and productivity in the regional airline industry. Transportation Journal 33(4), 21-32

[4] Elliot K \& Roach DW (1993), Service quality in the airline industry: Are carriers getting an unbiased evaluation from consumers? Journal of Professional Service Marketing 9(2), 71-82

[5] Tan C, Chen W, Liu H \& Rauterberg M (2009), Adapative framework and user preference modeling for economy class aircraft passenger seat. UKSim European Symposium on Computer Modeling and Simulation

[6] Romli FI, Abdul Rahman K \& Ishak F D (2016), In-flight food delivery and waste collection service: the passengers' perspective and potential improvement. IOP Conference Series: Material Science and Engineering 152(1), 012040

[7] Schmidt M, Heinemann P \& Hornung M (2017), Boarding and turnaround process assessment of single- and twin-aisle aircraft. 55th AIAA Aerospace Sciences Meeting

[8] Fuchte J, Dzikus N, Nagel B \& Gollnick V (2011), Cabin design for minimum boarding time. Deutscher Luft- und Raumfahrtkongress

[9] Jaehn F \& Neumann S (2015), Airplane boarding. European Journal of Operation Research 244(2), 339-359

[10] Zeineddine H (2017), A dynamically optimized aircraft boarding strategy. Journal of Air Transport Management 58, 144-151

[11] Nyquist DC \& McFadden KL (2008), A study of the airline boarding problem. Journal of Air Transport Management 14, 197-204

[12] Marelli S, Mattocks G \& Merry R (1998), The role of computer simulation in reducing airplane turn time. AERO Magazine

[13] Darby R (2010), Bin there, done that. Aerosafety World

[14] Chung CA (2012), Simulation design approach for the selection of alternative commercial passenger aircraft seating configurations. Journal of Aviation Technology and Engineering 2(1), 100-104

[15] Milne RJ \& Salari M (2016), Optimization of assigning passengers to seats on airplanes based on their carry-on luggage. Journal of Air Transport Management 54, 104-110 